\title{
Transformation rate of methyl isothiocyanate and 1,3-dichloropropene in water-saturated sandy subsoils
}

\author{
J. J. T. I. BOESTEN, L. J. T. VAN DER PAS, J. H. SMELT \& M. LEISTRA \\ The Winand Staring Centre for Integrated Land, Soil and Water Research (SC-DLO), P.O. \\ Box 125, NL 6700 AC Wageningen, Netherlands
}

Received 17 December 1990; accepted 17 May 1991

\begin{abstract}
The transformation rates of methyl isothiocyanate and 1,3-dichloropropene were studied in four water-saturated sandy subsoil materials collected between 2 and $4 \mathrm{~m}$ below the soil surface. The experiments were conducted in laboratory incubation systems at $10^{\circ} \mathrm{C}$. In three subsoil materials, transformation of methyl isothiocyanate was fast (less than $10 \%$ was left after 30 days), whereas in the case of the fourth material a half-life of approximately 35 days was found. With regard to the transformation of the $(Z)$ - and $(E)$-isomers of 1,3dichloropropene in the same subsoil materials, half-lives between 16 and 64 days were found. Incubation in systems where the subsoil materials had been exposed unintentionally to temperatures up to $30^{\circ} \mathrm{C}$ before adding the compounds, resulted in much lower transformation rates for methyl isothiocyanate (half-lives ranging from 150 to 570 days) and in only slightly lower rates for $(Z)$ - and $(E)$-1,3-dichloropropene (half-lives ranging from 38 to 76 days).
\end{abstract}

Keywords: transformation, subsoil, 1,3-dichloropropene, methyl isothiocyanate, groundwater contamination

\section{Introduction}

Metham-sodium (sodium methyldithiocarbamate) and 1,3-dichloropropene are used as soil fumigants against soil-borne diseases, mainly nematodes. For the most part, metham-sodium is rapidly transformed in the soil into methyl isothiocyanate which is the active compound (Smelt \& Leistra, 1974, Gerstl et al., 1977, Smelt et al., 1989a). Figure 1 gives the structural formulas of metham-sodium, methyl isothiocyanate and the isomers of 1,3-dichloropropene. Both methyl isothiocyanate and 1,3-dichloropropene are only weakly sorbed in soil. Smelt \& Leistra (1974) measured methyl isothiocyanate sorption by three soils and their results correspond with values of the organic-matter/water distribution ratio, $K_{\mathrm{om}}$, in the range from 2 to $4 \mathrm{dm}^{3} \mathrm{~kg}^{-1}$. Leistra (1970) found $K_{\mathrm{om}}$ values of the $(Z)$ - and $(E)$-isomers of 1,3-dichloropropene of $14-15 \mathrm{dm}^{3} \mathrm{~kg}^{-1}$. Results of laboratory studies on transfor- 
Metham-sodium

Methyl isothiocyanate

1,3-Dichloropropene<smiles>CNC(=S)[AsH-]N[NH2+]</smiles>

$\mathrm{H}_{3} \mathrm{C} \cdot \mathrm{N}=\mathrm{C}=\mathrm{S}$<smiles>ClC=CCCl</smiles>

(Z)<smiles>ClC=CCCl</smiles>

(E)

Fig. 1. Structural formulas of metham-sodium, methyl isothiocyanate and the $(Z)$ - and $(E)$-isomers of 1,3-dichloropropene.

mation rates in topsoil materials at $15{ }^{\circ} \mathrm{C}$ demonstrated half-lives for methyl isothiocyanate (assuming first-order kinetics) usually ranging between 4 and 20 days (Smelt et al., 1989a). For the isomers of 1,3-dichloropropene in similar studies halflives between 10 and 30 days were found (Roberts \& Stoydin, 1976; van Dijk, 1980). Leistra \& Frissel (1975) calculated leaching of (Z)-1,3-dichloropropene using a mathematical model for autumn application on two soil types and estimated that $0.1-4 \%$ of the dose leached to a depth of $1 \mathrm{~m}$ below the soil surface. In view of the similarities in sorption and transformation properties of 1,3-dichloropropene and methyl isothiocyanate, it could be expected that calculations for methyl isothiocyanate would result in roughly the same extent of leaching as that of $(Z)-1,3-$ dichloropropene. Consequently it could be expected that, under certain conditions, both methyl isothiocyanate and 1,3-dichloropropene leach to groundwater at measurable concentrations. This has been confirmed by field data: both soil fumigants have occasionally been detected in groundwater (Lagas et al., 1989; Leistra \& Boesten, 1989).

In the northeastern part of the Netherlands, starch-potatoes are being grown in a narrow crop rotation. In this area, metham-sodium and 1,3-dichloropropene are used on a large scale against plant parasitic nematodes (mainly the potato cyst nematode). The recommended application rate is approximately $150 \mathrm{~kg} \mathrm{ha}^{-1}$ for metham-sodium and $170 \mathrm{~kg} \mathrm{ha}^{-1}$ for 1,3-dichloropropene (van Rijn, 1989). In this area are also several pumping stations where groundwater is pumped for public water supply (usually from depths of around $40 \mathrm{~m}$ ). Because many agricultural fields are located in the neighbourhood of these pumping stations, it is appropriate that the risk of methyl isothiocyanate and 1,3-dichloropropene reaching the pumping wells be investigated. The travel time of water to the wells is usually about 10 years or more, therefore data on the transformation rate in water-saturated subsoil materials are relevant. In the literature such information for methyl isothiocyanate is not available. Leistra et al. (1991) studied the transformation rate of 1,3dichloropropene at $10{ }^{\circ} \mathrm{C}$ in subsoil materials from flower-bulb fields (located in the 
west of the Netherlands) with comparatively high $\mathrm{pH}$ values ( 7 to 8 ). They established that after 17 to 47 days $50 \%$ of both of the isomers of 1,3-dichloropropene were transformed. A priori, however it is not known whether these results can be extrapolated to other types of subsoils (with, for instance, lower $\mathrm{pH}$ values).

Accordingly, in the present study, transformation rates of methyl isothiocyanate and 1,3-dichloropropene have been measured in water-saturated subsoil materials collected in the northeastern part of the Netherlands.

\section{Materials and methods}

\section{Description and collection of subsoil samples}

The subsoil samples were collected from four agricultural locations listed in Table 1. The fields are all located in the northeastern part of Netherlands (the area where the soil fumigants are used on a large scale). The soils from Borgerswold and Valthermond are reclaimed peat soils with fine sandy subsoils. Those from Schipborg and Papenvoort are humic sand podsols. The Schipborg subsoil consists of an iron-rich fine sand with boulder clay. The Papenvoort subsoil is a fine sandy soil with some thin layers of coarse sand with gravel (moraine deposits). The groundwater tables were between 0.7 and $1.1 \mathrm{~m}$ below the soil surface at the time of sampling (March/April).

Three to six bore holes were made in each field within an area of $100 \mathrm{~m}^{2}$. When the groundwater table was reached, plastic casings $(1 \mathrm{~m}$ long, outer diameter $90 \mathrm{~mm}$, inner diameter $75 \mathrm{~mm}$ ) were placed. The holes were deepened to a depth of approximately $2.5 \mathrm{~m}$ by augering and bailing without additional water. The material from the permanent water-saturated layers (depths given in Table 1) was then collected using a stainless steel tube (lenght $0.5 \mathrm{~m}$, inner diameter $60 \mathrm{~mm}$ ). The closed upper end enabled connection to either a vacuum system or a pressurized nitrogen cylinder via plastic tubing and a three-way valve. A glass frit (diameter $40 \mathrm{~mm}$, pore size 100 $160 \mu \mathrm{m}$ ) mounted in the upper part of the sampling tube prevented soil particles entering into the plastic tubing. The sampling tube was placed in the bore hole by means of extension rods and then purged with nitrogen gas before it was pressed into

Table 1. Characteristics of the subsoils used in this study.

\begin{tabular}{llllllll}
\hline Location & $\begin{array}{l}\text { Depth } \\
\text { below } \\
\text { soil } \\
\text { surface } \\
(\mathrm{m})\end{array}$ & $\mathrm{pH}$ & $\begin{array}{l}\mathrm{CaCO}_{3} \\
(\%)\end{array}$ & $\begin{array}{l}\text { Organic } \\
\text { matter }(\%)\end{array}$ & $\begin{array}{l}\text { Redox } \\
\text { potential }(\mathrm{mV})\end{array}$ & $\begin{array}{l}\text { Clay }(<2 \mu \mathrm{m}) \\
(\%)\end{array}$ & $\begin{array}{l}\text { Silt }(2-50 \mu \mathrm{m}) \\
(\%)\end{array}$ \\
& & & & & & & \\
& & & & & & \\
Borgerswold & $2-3$ & 5.7 & 0.0 & 0.0 & $480-500$ & 3 & 7 \\
Schipborg & $2.5-3.5$ & 3.8 & 0.0 & 0.0 & $390-530$ & 8 & 9 \\
Valthermond & $2.5-3$ & 5.7 & 0.0 & 0.0 & $220-420$ & 4 & 5 \\
Papenvoort & $2.5-3.5$ & 4.5 & 0.0 & 0.1 & $360-500$ & 2 & 5 \\
\hline
\end{tabular}


the soil. Then the nitrogen pressure was changed into vacuum. Subsequently the sampling tube was pulled up and the casing tube pushed down to the next sampling depth. The pulling up and the catchment of the soil inside the sampler was improved by injecting pressurized nitrogen gas at the tube end via a thin steel pipe (inner diameter $2 \mathrm{~mm}$ ) situated inside the sampling tube. The sampling tube was emptied (by nitrogen pressure) into polyethene vessels $\left(30 \mathrm{dm}^{3}\right)$ containing already some groundwater, the reason being that a layer of water on the subsoil material would minimize contact with the air. The vessels were completely filled with subsoil material and groundwater (without leaving a headspace) and closed hermetically and stored in the laboratory at $10^{\circ} \mathrm{C}$.

In the field, the redox potentials of the subsoils were measured in two to four bore holes using the method described by Leistra et al. (1991). The potentials were measured 30 to $60 \mathrm{~min}$ after inserting the Pt electrodes into the subsoils. The ranges found are given in Table 1.

\section{Subsoil incubations}

The incubations were started three to four weeks after collecting the subsoils in the field. Two incubation systems were used. The first system consisted of a glass flask $\left(500 \mathrm{~cm}^{3}\right)$ with a ground glass stopper. The seal of the stopper was continuously kept wet to minimize loss of methyl isothiocyanate and 1,3-dichloropropene via the gas phase. Previous experiments in this system with pure $(Z)$ - and $(E)-1,3-$ dichloropropene by Smelt et al. (1989b) demonstrated only a small loss $(<7 \%$ in 115 days at $20^{\circ} \mathrm{C}$ ). It may be expected that the loss of methyl isothiocyanate via the gas phase is even smaller due to the saturated vapour pressure of methyl isothiocyanate being lower than that of the isomers of 1,3-dichloropropene (at $20{ }^{\circ} \mathrm{C} 17 \mathrm{hPa}(1 \mathrm{hPa}=1 \mathrm{mbar})$ for methyl isothiocyanate as compared to $25-33$ $\mathrm{hPa}$ for the isomers of 1,3-dichloropropene; Goring, 1962; Smelt \& Leistra, 1974). Nevertheless, a second incubation system which was completely airtight was used because very low transformation rates were invisaged, necessitating a system without any loss via the vapour phase.

The second incubation system consisted of a glass flask $\left(500 \mathrm{~cm}^{3}\right)$ onto which a glass cylinder ( $30 \mathrm{~mm}$ high and $45 \mathrm{~mm}$ in diameter) was melted. After filling the system with subsoil material, a glass adapter (lenght $70 \mathrm{~mm}$ ) decreasing in diameter from $45 \mathrm{~mm}$ at the bottom to $2 \mathrm{~mm}$ at the top, was melted onto this cylinder. The $2 \mathrm{~mm}$ opening was sealed by melting following addition of the compounds. In this paper the first incubation system will be referred to as 'the system with stopper' and the second 'the system with melted seal'.

While the flasks were being filled with a subsoil material, the corresponding collection vessel was flushed with nitrogen gas. The subsoil was transferred from the vessels into the incubation systems using a steel cylinder (inner diameter $16 \mathrm{~mm}$, length $295 \mathrm{~mm}$ ). The top of the cylinder enabled connection to either a vacuum system or a pressurized nitrogen cylinder via plastic tubing and a three-way valve. Two cylinders full content were added to each system and the added mass was weighed. A cylinder full content was regularly emptied onto an aluminium tray for determina- 
tion of the moisture content. The systems were flushed with nitrogen gas during filling. A volume of $10 \mathrm{~cm}^{3}$ groundwater (collected at the same site as the material) was added to each system, creating a water-saturated layer of subsoil material covered by a water layer of approximately $5 \mathrm{~mm}$. The mass of solid phase in the systems was found to be (on average) $0.20,0.15,0.20$ and $0.19 \mathrm{~kg}$ for the subsoil materials from Borgerswold, Schipborg, Valthermond and Papenvoort, respectively. The mass of liquid phase in the systems amounted to (on average) 54, 55, 54 and $55 \mathrm{~g}$, respectively. The filling procedure took about $1.5 \mathrm{~h}$, all flasks being exposed to room temperature $\left( \pm 25^{\circ} \mathrm{C}\right)$ during this period. The flasks of the system with stopper where flushed with $1 \mathrm{dm}^{3}$ of nitrogen gas, closed with a stopper and stored in the dark at $10^{\circ} \mathrm{C}$. The flasks of the sytem with melted seal were transferred to a glass-blower (to melt the glass adapter on the glass cylinder), which led to an unintentional exposure to temperatures up to about $30^{\circ} \mathrm{C}$ on that day. Once back in the laboratory, these flasks were flushed with $1 \mathrm{dm}^{3}$ of nitrogen gas, closed with parafilm and stored in the dark at $10^{\circ} \mathrm{C}$. The period between filling the flasks and adding the compounds was 12 days (for both incubation systems). After flushing the flasks with $1 \mathrm{dm}^{3}$ of nitrogen gas, the compounds were added in $1 \mathrm{~cm}^{3}$ of an aqueous solution which contained either analytical grade methyl isothiocyanate (about $50 \mathrm{~g} \mathrm{~m}^{-3}$ ) or analytical grade 1,3-dichloropropene (about $24 \mathrm{~g} \mathrm{~m}^{-3}$ of each of the isomers). To determine the mass of compound added to the system, portions (in total 24) of $1 \mathrm{~cm}^{3}$ of the aqueous solutions were regularly injected directly into $10 \mathrm{~cm}^{3}$ of ethyl acetate (for methyl isothiocyanate) or into $10 \mathrm{~cm}^{3}$ of hexane (for 1,3-dichloropropene). Addition of the $1 \mathrm{~cm}^{3}$ of the aqueous solution to the incubation systems was alternated with addition to ethyl acetate or hexane. The mass of methyl isothiocyanate was found to be $58( \pm 2) \mu \mathrm{g}$ and the masses of $(Z)$ - and $(E)$ 1,3-dichloropropene were both found to be $22( \pm 1) \mu \mathrm{g}$.

All the flasks were closed immediately after addition of the compounds, those of the first system with the ground-glass stopper and those of the second system by melting the top of the glass adapter (within $10 \mathrm{~s}$ ).

\section{Measurement of redox potential during the incubations}

Some of the flasks of the system with stopper were used for measurement of redox potential several times during the incubations (these flasks were not used for residue determinations). Each time the measurement was carried out in only one flask per subsoil. The redox potential was measured with a $\mathrm{Pt}$ electrode and an $\mathrm{Ag} / \mathrm{AgCl}$ reference electrode. The Pt electrode was inserted into the subsoil material and the potential measured after $30 \mathrm{~min}$.

\section{Extraction and analysis}

At several times after addition of methyl isothiocyanate or 1,3-dichloropropene, two or three flasks per subsoil series of the system with stopper and one or two flasks of the system with melted seal were extracted. First $10 \mathrm{~cm}^{3}$ of solvent (ethyl acetate for methyl isothiocyanate and hexane for 1,3-dichloropropene) was injected 
into the flask. After $10 \mathrm{~min}, 200 \mathrm{~cm}^{3}$ distilled water was added and the flasks were connected to a Dean and Stark receiver. The samples were extracted by heating the flasks to $100{ }^{\circ} \mathrm{C}$ on a Kjeldahl apparatus for $30 \mathrm{~min}$. The ethyl acetate phase (methyl isothiocyanate) was dried over anhydrous $\mathrm{Na}_{2} \mathrm{SO}_{4}$.

The concentration of methyl isothiocyanate in ethyl acetate was measured with a Pye-Unicam gas chromatograph equipped with a flame photometer detector, operated in the sulphur mode (394 nm filter). The glass column (lenght $1.4 \mathrm{~m}$; inner diameter $4 \mathrm{~mm}$ ) was packed with $3 \%$ Carbowax 20M on Chromosorb W AWDMCS, particle size $0.15-0.18 \mathrm{~mm}$. The flow rate of the carrier gas (nitrogen) was $0.5 \mathrm{~cm}^{3} \mathrm{~s}^{-1}$. The temperatures of the injector, column and detector were 240,100 and $260^{\circ} \mathrm{C}$, respectively. The retention time was $1.2 \mathrm{~min}$. The injected volume of ethyl acetate was 1 or $3 \mathrm{~mm}^{3}$. Standard solutions of methyl isothiocyanate in ethyl acetate were injected regularly. Concentrations were calculated from peak heights. The detection limit of the method was $0.1 \mu \mathrm{g}$ (i.e. $0.2 \%$ of the dose of $58 \mu \mathrm{g}$ ).

The concentrations of the $(Z)$ - and $(E)$-isomers of 1,3-dichloropropene in hexane were measured using a HRGC-5300-MEGA Carlo Erba gas chromatograph equipped with a ${ }^{63 \mathrm{Ni}}$ electron-capture detector. The widebore fused-silica column (Chrompack, lenght $25 \mathrm{~m}$, inner diameter $0.5 \mathrm{~mm}$ ) was coated with CP-Carbowax 52-CB (film thickness $2.6 \mu \mathrm{m}$ ). The carrier gas was helium with a flow rate of 0.17 $\mathrm{cm}^{3} \mathrm{~s}^{-1}$ and the make-up gas for the detector was nitrogen with a flow rate of 0.17 $\mathrm{cm}^{3} \mathrm{~s}^{-1}$. The chromatograph operated in the split mode (split ratio 4:1). The temperatures of the injector, outlet and detector were 150,260 and $270{ }^{\circ} \mathrm{C}$. The temperature of the column was $100^{\circ} \mathrm{C}$ for the first $300 \mathrm{~s}$ after injection and then it increased at $0.7^{\circ} \mathrm{C} \mathrm{s}^{-1}$ to $150^{\circ} \mathrm{C}$. The retention time was $3.0 \mathrm{~min}$ for the $(Z)$-isomer and $4.2 \mathrm{~min}$ for the $(E)$-isomer. The injected volume of hexane was $1 \mathrm{~mm}^{3}$. Standard solutions of the isomers in hexane were injected regulary. Concentrations were derived from peak heights. The detection limit of the method was $0.05 \mu \mathrm{g}$ for each of the isomers (i.e. $0.2 \%$ of the dose of $22 \mu \mathrm{g}$ ).

The recoveries of the extraction procedures were determined by comparing the masses extracted within 1 day after addition to the incubation systems to the masses added to these systems. The recoveries were found to be $97 \pm 2 \%$ for methyl isothiocyanate, $64 \pm 7 \%$ for (Z)-1,3-dichloropropene and $59 \pm 6 \%$ for $(E)$-1,3dichloropropene. The masses measured were not corrected for these recoveries.

\section{Results}

As shown by Figure 2, the redox potential in the system with stopper was fairly constant in time for each subsoil material. In general, the values found in the incubation systems (Figure 2) corresponded reasonably well with the range of the values found in the field (Table 1). Consequently the transfer of the subsoil materials to the laboratory and subsequent incubation had had no significant effect on the redox potentials of the subsoil materials.

The results for methyl isothiocyanate in the system with stopper (Figure 3) show that transformation in the subsoil material from Borgerswold was very fast: after 14 to 28 days less than $1 \%$ was left and after 70 days less than $0.2 \%$ (detection 


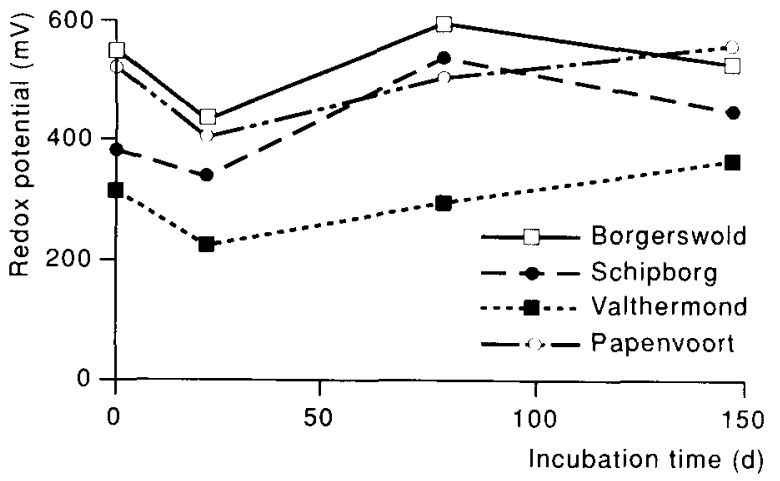

Fig. 2. Redox potential as a function of incubation time in the subsoil materials in the flasks of the system with stopper.

limit). The transformation in subsoil material from Schipborg could be reasonably described by first-order kinetics as shown in Figure 3a; the half-life was calculated to be 6 days. In the subsoil material from Valthermond (Figure 3b), although the residues decreased to below $10 \%$ of the dose within approximately 30 days, the decrease thereafter was much slower. During the first 70 days of the experiment the transformation in the subsoil material from Papenvoort was much slower than that in the other subsoil materials. As shown by Figure $3 \mathrm{~b}$, the transformation rate in this material could be roughly described by first-order kinetics; the half-life was calculated to be 35 days.

The transformation rate of methyl isothiocyanate in the system with melted seal
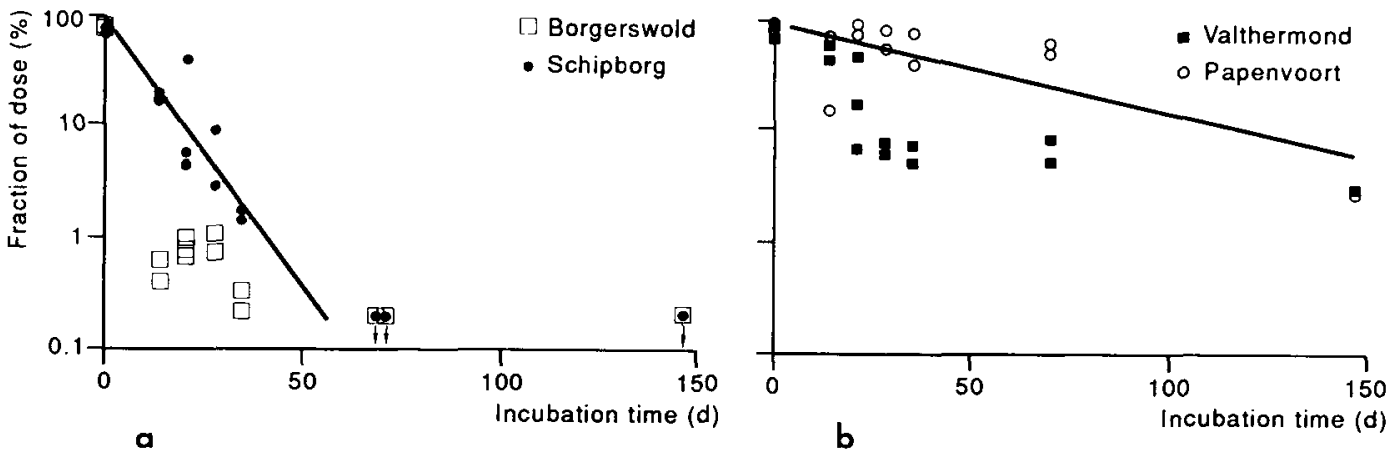

Fig. 3. Remaining fraction of methyl isothiocyanate as a function of incubation time in the subsoil materials in the system with stopper. Arrows indicate that the corresponding points were below the limit of detection. (a) Borgerswold and Schipborg; the line is a linear regression approximation for Schipborg assuming first-order kinetics. (b) Valthermond and Papenvoort; the line is a linear regression approximation for Papenvoort assuming first-order kinetics. 
could be reasonably well described by first-order kinetics up to the end of the experiment (205 days after addition of the compounds). Half-lives were estimated by linear regression and values of approximately $240,560,150$ and 570 days were found for the subsoil materials from Borgerswold, Schipborg, Valthermond and Papenvoort, respectively. Two out of 12 points for the Borgerswold material (with only $2 \%$ remaining after 42 days and only $0.2 \%$ after 205 days) were not included in the regression analysis. The same holds for two out of 11 points for the Valthermond material: $8 \%$ after 147 days and $5 \%$ after 205 days. These measurements show that in some incubation flasks the transformation rate has been comparatively high. However, in most instances transformation of methyl isothiocyanate in the system with melted seal proceeded much slower than in the system with stopper.

The results for 1,3-dichloropropene in the system with stopper (Figure 4) show that the transformation in general could be described well by first-order kinetics. The points measured after 147 days in the subsoil material from Schipborg were clear outliers and were therefore not included in the linear regression analysis for the calculation of the half-lives. Table 2 gives the calculated half-lives. The data in Figure 4 and Table 2 show that the differences between the $(Z)$ - and the $(E)$-isomers were generally small (the difference was considerable only in the case of the subsoil material from Schipborg).
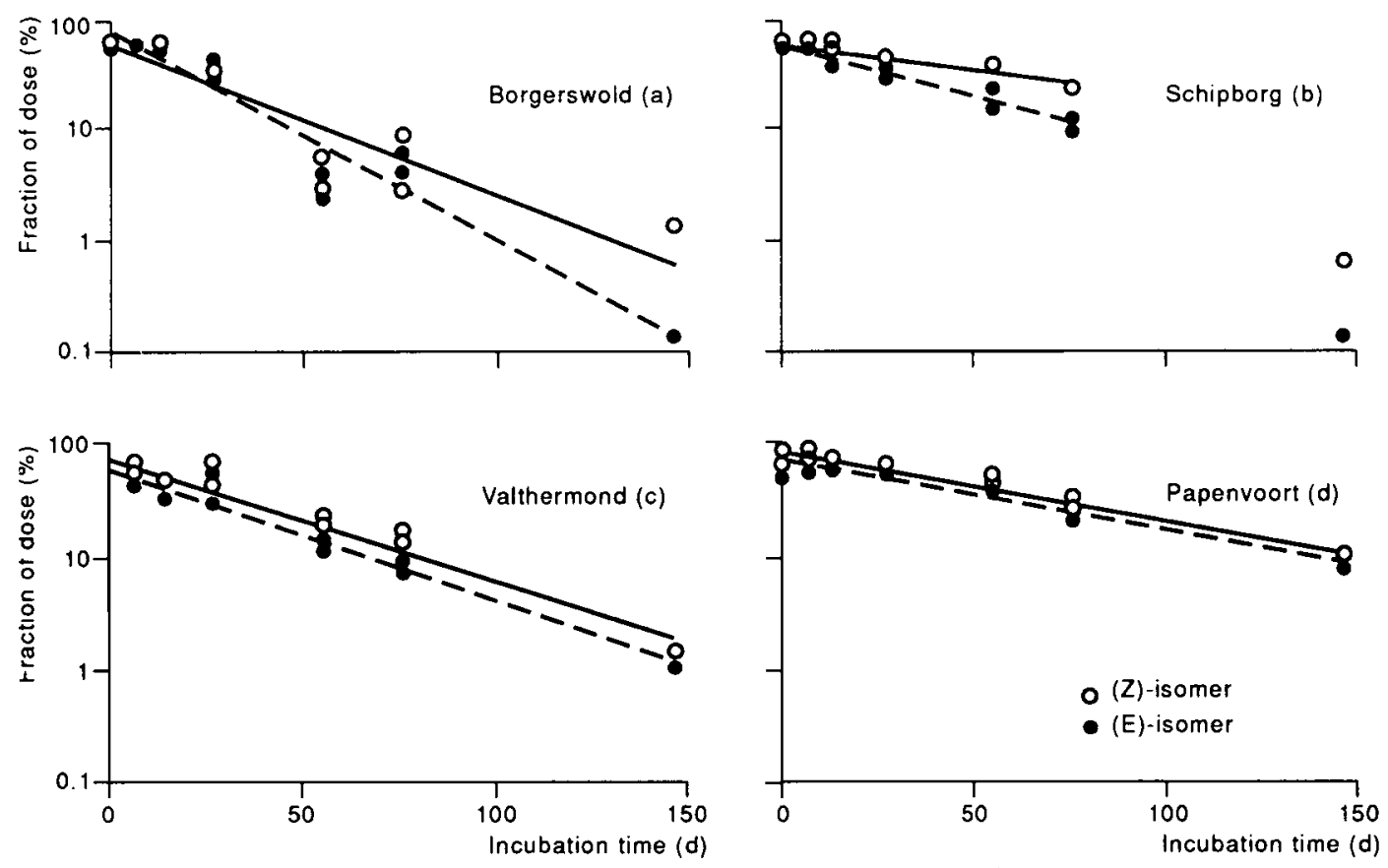

Fig. 4. Remaining fraction of the $(Z)$ - and $(E)$-isomers of 1,3-dichloropropene as a function of incubation time in the subsoil materials in the system with stopper. The lines are linear regression approximations assuming first-order kinetics $(-(Z)$-isomer; $---(E)$-isomer $)$. 
Table 2. Half-lives for the transformation of the $(Z)$ - and $(E)$-isomers of 1,3-dichloropropene in the incubation systems with stopper and with melted seal at $10^{\circ} \mathrm{C}$.

\begin{tabular}{|c|c|c|c|c|}
\hline \multirow[t]{3}{*}{ Subsoil material } & \multicolumn{4}{|c|}{ Half-lives (days) } \\
\hline & \multicolumn{2}{|c|}{$(Z)$-isomer } & \multicolumn{2}{|c|}{$(E)$-isomer } \\
\hline & stopper & melted seal & stopper & melted seal \\
\hline Borgerswold & 22 & 66 & 16 & 63 \\
\hline Schipborg & 64 & 68 & 33 & 56 \\
\hline Valthermond & 28 & 42 & 26 & 38 \\
\hline Papenvoort & 52 & 70 & 53 & 76 \\
\hline
\end{tabular}

The transformation rate of the isomers of 1,3-dichloropropene in the system with melted seal could always be described well by first-order kinetics. The corresponding half-lives (obtained by linear regression analysis) are given in Table 2. As shown by this table, differences between the $(Z)$ - and the $(E)$-isomers were always small for this system. Table 2 also shows that the half-lives in the system with melted seal were always higher than the corresponding values in the system with stopper. For the subsoil material from Borgerswold in particular, the difference between the two systems was large (a factor 3 to 4 ). For the other subsoil materials, the difference was comparatively small (always less than a factor of 2 ).

\section{Discussion and conclusions}

The large difference in transformation rate of methyl isothiocyanate between the incubation system with stopper and the system with melted seal, is remarkable. It is highly unlikely that this difference between the two systems is the result of loss via the gas phase in the system with stopper in view of the earlier check experiments by Smelt et al. (1989b) cited in Section 2.2 and taking into consideration the measured declines in Figure 3 (which at times proceeded very rapidly). The main difference between the two systems with respect to the treatment of the subsoil materials is the (unintentional) exposure of the system with melted seal to temperatures up to $30^{\circ} \mathrm{C}$ before adding the compounds. In the temperate climate of the Netherlands, soil temperature between depths of 2 and $3 \mathrm{~m}$ below the soil surface remains very close to $10{ }^{\circ} \mathrm{C}$. A possible explanation of the difference between the two systems could be that the transformation of methyl isothiocyanate in the subsoil is mainly microbial. In that case, the increase of the temperature in the system with melted seal may have inactivated a large fraction of the micro-organisms responsible for the (comparatively fast) transformation in the system with stopper (shown in Figure 3). Another possibility would be that the increase of the temperature could have influenced factors responsible for abiotic transformation of methyl isothiocyanate.

The results of our experiments with methyl isothiocyanate in the incubation system with melted seal show that under certain conditions this compound may be very stable in aqueous systems. This is compatible with information in literature on the 
stablility in water or in aqueous buffers. Ashley \& Leigh (1963) found the loss of this compound in distilled water to be approximately $10 \%$ after 24 days at room temperature. Smelt (personal communication, 1989) found a loss of methyl isothiocyanate in demineralized water of approximately $3 \%$ after 30 days at $13{ }^{\circ} \mathrm{C}$. Gerstl et al. (1977) reported that methyl isothiocyanate was stable for several weeks in water and in an aqueous $\mathrm{CaCl}_{2}$ solution at room temperature.

Leistra et al. (1991) measured transformation of the isomers of 1,3dichloropropene in three subsoil materials with $\mathrm{pH}$ values of 7 to 8 at $10^{\circ} \mathrm{C}$. They found that after 17 to 47 days $50 \%$ of the isomers was transformed. These values correspond well with the values of the half-lives which we found in the system with stopper (Table 2). They also found that the transformation rate became faster than corresponding with a first-order rate equation after approximately $80 \%$ transformation had taken place. We found a similar trend in the subsoil material from Schipborg although based on only one measured point per isomer (Figure 4b).

In our incubation studies the transformation of the isomers of 1,3dichloropropene always proceeded at a reasonable rate: the highest half-life in Table 2 is 76 days. This may possibly be explained by the hydrolysis of the isomers reported in the literature. McCall (1987) found a half-life for the two isomers in aqueous phosphate buffers of 51 days at $10^{\circ} \mathrm{C}$. The half-lives were independent of $\mathrm{pH}$ over the range of $\mathrm{pH} 5$ to 9 . Smelt et al. (1989b) found a half-life of the two isomers in distilled water at $10^{\circ} \mathrm{C}$ of 53 days. These half-lives are within the range of the values given in Table 2 which suggests that hydrolysis (an abiotic process) significantly contributed to the transformation of the isomers of 1,3-dichloropropene in our incubation studies.

The sometimes large differences found between the two incubation systems imply that differences in treatment of the subsoil materials between collection in the field and start of the experiment in the laboratory may influence the results considerably. The subsoil materials in the incubation system with stopper were handled closer to field-alike conditions in the period before the start of the experiment than those in the system with melted seal. Therefore it may be expected that the transformation rates found in the system with stopper resemble the transformation rates in the field better than the rates found in the system with melted seal. In general, little is known of the influence of pretreatment of subsoil materials on the transformation rate of pesticides. Research on this subject is urgently needed particularly as the interest in transformation in subsoils in increasing (Leistra, 1988).

It is very well possible that micro-organisms contributed significantly to the transformation in our incubation studies in view of the substantial concentrations of bacteria that have been found in subsoils, even at large depths (van Beelen \& FleurenKemila, 1989). It has been suggested in literature that microbial transformation of organic chemicals could considerably slow down when the concentration of the chemical decreases below a certain threshold level (Alexander, 1985). Our results in Figures 3 and 4 did not indicate such an effect (only in the methylisothiocyanate/Valthermond system the decline slowed down considerably when approximately $10 \%$ was left).

Travel times of methyl isothiocyanate and the isomers of 1,3-dichloropropene to 
deep groundwater (e.g. $40 \mathrm{~m}$ ) could be expected to be in the order of 10 years or more. This is a long time compared to the time scale of our experiments (Figures 3 and 4). Consequently one could expect that only very low concentrations of methyl isothiocyanate and of the isomers of 1,3-dichloropropene would penetrate to deep groundwater. This has in general been confirmed by monitoring studies conducted in areas where these fumigants had been used on a large scale (Maddy et al., 1982; Leistra \& Boesten, 1989).

Our study does not provide information on the transformation products of methyl isothiocyanate and 1,3-dichloropropene. To the best of our knowledge no information is available in literature as to which transformation products are formed in subsoil materials. In topsoil materials no distinct transformation products have been identified for methyl isothiocyanate (Kötter et al., 1961). Roberts \& Stoydin (1976) studied the transformation of the $(Z)$ - and $(E)$-isomers of 1,3dichloropropene in topsoil materials and they found the $(Z)$ - and $(E)$-isomers of 3chloroallyl alcohol to be the main transformation products. These are formed by hydrolysis of 1,3-dichloropropene, so one may expect these 3-chloroallyl alcohols to also be the main transformation products in aerobic subsoil materials. Leistra et al. (1991) studied the transformation rate of the isomers of 3-chloroallyl alcohol in subsoil materials from flower-bulb fields with $\mathrm{pH}$ values of 7 to 8 . They found a comparatively fast transformation (50\% transformed after periods varying between approximately 2 weeks and a few months). Further research on transformation rates of 3-chloroallyl alcohols in a wider range of subsoils is advisable.

\section{Acknowledgements}

We thank the Province of Drenthe for its financial support. The research was part of the Netherlands Integrated Soil Research Programme.

\section{References}

Alexander, M., 1985. Biodegradation of organic chemicals. Environmental Science and Technology 18: $106-111$.

Asley, M. G., \& B. L. Leigh, 1963. The action of metham-sodium in soil. I. Development of an analytical method for the determination of methyl isothiocyanate residues in soil. Journal of the Science of Food and Agriculture 14: 148-153.

Beelen, P. van \& A. K. Fleuren-Kemila, 1989. Enumeration of anaerobic and oligotrophic bacteria in subsoils and sediments. Journal of Contaminant Hydrology 4: 275-284.

Dijk, H. van, 1980. Dissipation rates in soil of 1,2-dichloropropane and 1,3-dichloropropenes. Pesticide Science 11: 625-632.

Gerstl, Z., U. Mingelgrin \& B. Yaron, 1977. Behavior of vapam and methyl isothiocyanate in soils. Soil Science Society of America Journal 41: 545-548.

Goring, C. A. I., 1962. Theory and principles of soil fumigation. Advances in Pesticide Control Research 5: $47-84$.

Kötter, K., J. Willenbrink \& K. Junkmann, 1961. Der Abbau von 35S-markierten Methylsenföl in verschiedenen Boden. Zeitschrift für Pflanzenkrankheiten und Pflanzenschutz 68: 407-411.

Lagas, P., B. Verdam \& J. P. G. Loch, 1989. Threat of soil water quality by pesticides. (In Dutch). $\mathrm{H}_{2} \mathrm{O} 22$ : 422-427. 


\section{J. J. T. I. BOESTEN, L. J. T. VAN DER PAS, J. H. SMELT AND M. LEISTRA}

Leistra, M., 1970. Distribution of 1,3-dichloropropene over the phases in soil. Journal of Agricultural Food Chemistry 18: 1124-1126.

Leistra, M. \& M. J. Frissel, 1975. Computations on the material balance of pesticides in soil. In: F. Coulston \& F. Korte (Eds), Environmental Quality and Safety, Supplement Volume III, Pesticides, p. 817 828. George Thieme Publishers, Stuttgart, Germany.

Leistra, M., 1988. Behaviour and significance of pesticide residues in ground water. Aspects of Applied Biology 17: 223-229.

Leistra, M. \& J. J. T. I. Boesten, 1989. Pesticide contamination of groundwater in western Europe. Agriculture, Ecosystems and Environment 26: 369-389.

Leistra, M., A. E. Groen, S. J. H. Crum \& L. J. T. van der Pas, 1991. Transformation rate of 1,3dichloropropene and 3-chloroallyl alcohol in topsoil and subsoil material of flower-bulb fields. Pesitcide Science 31: 197-207.

Maddy, K. T., H. R. Fong, J. A. Lowe, D. W. Conrad \& A. S. Frederickson, 1982. A study of well water in selected California communities for residues of 1,3-dichloropropene, chloroallyl alcohol and 49 organophosphate or chlorinated hydrocarbon pesticides. Bulletin of Environmental Contamination and Toxicology 29: 354-359.

McCall, P. J., 1987. Hydrolysis of 1,3-dichloropropene in dilute aqueous solution. Pesticide Science 19: 235-242.

Van Rijn, J. F. A. T., 1989. Crop Protection Guide. (In Dutch). Plant Protection Service, Wageningen, Netherlands.

Roberts, T. R. \& G. Stoydin, 1976. The degradation of $(Z)$ - and $(E)$-1,3-dichloropropenes and 1,2dichloropropane in soil. Pesticide Science 7: 325-335.

Smelt. J. H. \& M. Leistra, 1974. Conversion of metham-sodium to methyl isothiocyanate and basic data on the behaviour of methyl isothiocyanate in soil. Pesticide Science 5: 401-407.

Smelt, J. H., S. H. J. Crum \& W. Teunissen, 1989a. Accelerated transformation of the fumigant methyl isothiocyanate in soil after repeated application of metham-sodium. Journal of Environmental Science and Health B24: 437-455.

Smelt, J. H., W. Teunissen, S. J. H. Crum \& M. Leistra, 1989b. Accelerated transformation of 1,3dichloropropene in loamy soils. Netherlands Journal of Agricultural Science 37: 173-183. 